\title{
HUBUNGAN UMUR, TINGKAT PENGETAHUAN DAN PARITAS IBU NIFAS DENGAN PELAKSANAAN BOUNDING ATTACHMENT
}

\author{
A Asrina, Siti Nunung Nurjannah, Anggit Kartikasari, Lela Budiarti \\ STIKes Kuningan \\ asrina.andiamir@gmail.com
}

\begin{abstract}
Abstrak
Perkembangan bayi normal sangat tergantung dari respon kasih sayang antara ibu dengan bayi. Respon kasih sayang antara ibu dan bayinya dapat terbentuk melalui proses bounding attachment. Kurangnya respon kasih sayang antara ibu dan bayi dalam bentuk bounding attachment ini akan mempengaruhi proses perkembangan bayi bahkan meningkatkan angka kematian bayi. Penelitian ini bertujuan untuk mengetahui hubungan antara umur, paritas dan pengetahuan dengan pelaksanaan bounding attachment pada masa nifas. Jenis penelitian ini adalah penelitian analitik dengan rancangan penelitian cross sectional. Teknik pengambilan sampel menggunakan accidental sampling berjumlah $30 \mathrm{ibu}$ nifas. Variabel umur dikategorikan beresiko bila responden berusia $<20$ dan $>35$ tahun, sedangkan variabel paritas dikategorikan multipara bila pada penelitian ini merupakan persalinan ke 2-4, dan primipara dikategorikan pada responden bila pada penelitian ini merupakan persalinan yang pertama. Analisis data menggunakan uji korelasi Spearman Rank. Hasil penelitian didapatkan responden yang memiliki umur tidak beresiko $(85,7 \%)$, paritas multipara $(88,9 \%)$ dan pengetahuan baik $(100 \%)$ sebagian besar melakukan bounding attachment. Responden yang memiliki umur beresiko (77,8\%), paritas primipara (66,7\%) dan pengetahuan kurang (70\%) sebagian besar tidak melakukan bounding attachment. Kesimpulan penelitian ini adalah terdapat hubungan $(p=0,001<0,05)$ antara umur, paritas dan pengetahuan dengan pelaksanaan bounding attachment pada masa nifas.
\end{abstract}

Kata kunci : Umur, Pengetahuan, Paritas, Bounding Attachment, Nifas

\section{Pendahuluan}

Bayi baru lahir membutuhkan

stimuli dari lingkungannya, terutama lingkungan sosial untuk meningkatkan potensi perkembangannya (Kuntjojo, 2010). Perkembangan bayi normal sangat 
JURNAL ILMU KESEHATAN BHAKTI HUSADA:

HEALTH SCIENCES JOURNAL, VOL. 12 No. 01, JUNI 2021

DOI: $\underline{10.34305 / \mathrm{jikbh} . v 12 \mathrm{i} 1.259}$
Ciptaan disebarluaskan di bawah

Lisensi Creative Commons Atribusi-

NonKomersial-BerbagiSerupa 4.0

Internasional. tergantung dari respon kasih sayang antara ibu dengan bayi. Respon kasih sayang antara ibu dan bayinya dapat terbentuk melalui proses bounding attachment. Bounding attachment adalah sentuhan awal/kontak kulit antara ibu dan bayi pada menit-menit pertama sampai beberapa jam setelah kelahiran bayi. Ada berbagai cara untuk melakukan bounding attachment diantaranya Inisiasi Menyusui Dini (IMD) dan pemberian ASI Eksklusif (Susilawati et al., 2020).

Kurangnya respon kasih sayang antara ibu dan bayi dalam bentuk bounding attachment ini akan mempengaruhi proses perkembangan bayi bahkan meningkatkan angka kematian bayi. Data Profil Kesehatan Indonesia menunjukkan capaian Angka Kematian Bayi (AKB) di Indonesia 24 per 1.000 kelahiran hidup, sedangkan di Jawa Barat 3,4 per 1.000 kelahiran hidup. Angka ini masih cukup tinggi dibandingkan dengan target SDGs dalam mengurangi dan mengakhiri kematian bayi dan balita yang dapat dicegah menjadi 12 per 1.000 kelahiran hidup pada AKN sedangkan AKB turun menjadi 25 per 1.000 kelahiran hidup (Dinas Kesehatan Provinsi Jawa Barat, 2017; RI, 2020).

Bounding attachment memegang peranan penting yang akan memberikan kenyamanan dan kehangatan pada si bayi, dimana bayi akan merasa dicintai, diperhatikan, dipercayai serta dapat menumbuhkan sikap sosial, sehingga bayi dapat merasa aman dan berani untuk melakukan eksplorasi (Astuti, 2013).

Mengingat pentingnya ASI dan keterikatan kasih sayang (bounding attachment) antara ibu dan anak maka penting untuk mewujudkan kasih sayang tersebut. Beberapa penelitian menunjukkan menunjukkan bahwa beberapa faktor yang ikut mempengaruhi pelaksanaan bounding attachment antara lain umur ibu nifas, tingkat pengetahuan serta paritas ibu (Susilawati et al., 2020).

Umur dapat mempengaruhi kesiapan mental ibu terhadap bayinya, begitu juga dengan paritas ibu karena berhubungan dengan pengalaman yang ibu miliki (Wahyuni, 2016). Selain itu, ibu nifas yang memiliki pengetahuan baik melakukan bounding attachment untuk mendapatkan pelayanan kesehatan pada bayi baru lahir dengan merawat bayi nya secara mandiri tidak hanya sepenuhnya dari bantuan keluarga. Hal ini dilakukan karena ibu mengetahui manfaat dari bounding attachment tersebut (Kurnia, 2013). 
JURNAL ILMU KESEHATAN BHAKTI HUSADA:

HEALTH SCIENCES JOURNAL, VOL. 12 No. 01, JUNI 2021

DOI: $\underline{10.34305 / \mathrm{jikbh} . v 12 \mathrm{i} 1.259}$
Ciptaan disebarluaskan di bawah

Lisensi Creative Commons Atribusi-

NonKomersial-BerbagiSerupa 4.0

Internasional.

\section{Metode}

Jenis penelitian ini adalah penelitian analitik dengan rancangan penelitian cross sectional. Teknik pengambilan sampel menggunakan accidental sampling berjumlah $30 \mathrm{ibu}$ nifas. Variabel umur dikategorikan beresiko bila responden berusia $<20$ dan $>35$ tahun, sedangkan variabel paritas dikategorikan multipara bila pada penelitian ini merupakan persalinan ke 2-4, dan primipara dikategorikan pada responden bila pada penelitian ini merupakan persalinan yang pertama. Analisis data menggunakan uji Chi-square.

Hasil

Tabel 1. Distribusi Frekuensi

\begin{tabular}{cccc}
\hline Variabel & Kategori & Frekuensi & Persentase (\%) \\
\hline \multirow{3}{*}{ Umur } & Tidak Berisiko & 21 & 70 \\
\cline { 2 - 4 } & Berisiko & 9 & 30 \\
\cline { 2 - 4 } Paritas & Total & $\mathbf{3 0}$ & $\mathbf{1 0 0}$ \\
\cline { 2 - 4 } & Multipara & 18 & 60 \\
\cline { 2 - 4 } & Primipara & 12 & 40 \\
\hline \multirow{3}{*}{ Pengetahuan } & Total & $\mathbf{3 0}$ & 36,7 \\
\cline { 2 - 4 } & Baik & 11 & 30 \\
\cline { 2 - 4 } & Cukup & 10 & 33,3 \\
\hline \multirow{2}{*}{ Bounding } & Kurang & $\mathbf{3 0}$ & 66,7 \\
\cline { 2 - 4 } Attachment & Total & 20 & 33,3 \\
\cline { 2 - 4 } & Ya & 10 & $\mathbf{1 0 0}$ \\
\hline
\end{tabular}

Sumber : Data Primer

Ibu nifas yang menjadi sampel dalam $\quad(70 \%), \quad$ multipara $\quad(60 \%), \quad$ memiliki penelitian ini didominasi oleh ibu nifas yang pengetahuan baik $(36,7 \%)$ dan melakukan berumur tidak beresiko yaitu 20-35 tahun bounding attachment (66,7\%).

Tabel 2. Hubungan umur, paritas dan pengetahuan dengan pelaksanaan bounding attachment

\begin{tabular}{|c|c|c|c|c|c|c|c|}
\hline \multirow{3}{*}{ Variabel } & \multicolumn{4}{|c|}{ Bounding Attachment } & \multirow{2}{*}{\multicolumn{2}{|c|}{ Total }} & \multirow{3}{*}{ Nilai $p$} \\
\hline & \multicolumn{2}{|c|}{ Ya } & \multicolumn{2}{|c|}{ Tidak } & & & \\
\hline & f & $\%$ & f & $\%$ & $\mathbf{N}$ & $\%$ & \\
\hline \multicolumn{8}{|l|}{ Umur } \\
\hline Tidak Berisiko & 18 & 85,7 & 3 & 14,3 & 21 & 100 & \multirow{2}{*}{0,001} \\
\hline Berisiko & 2 & 22,2 & 7 & 77,8 & 9 & 100 & \\
\hline \multicolumn{8}{|l|}{ Paritas } \\
\hline Multipara & 16 & 88,9 & 2 & 11,1 & 18 & 100 & \multirow[t]{2}{*}{0,001} \\
\hline Primipara & 4 & 33,3 & 8 & 66,7 & 12 & 100 & \\
\hline
\end{tabular}




\begin{tabular}{cccccccc}
\hline Baik & 11 & 100 & 0 & 0 & 11 & 100 \\
\cline { 1 - 5 } Cukup & 6 & 66,7 & 3 & 33,3 & 9 & 100 & 0,001 \\
\cline { 1 - 3 } Kurang & 3 & 30 & 7 & 70 & 10 & 100 &
\end{tabular}

Sumber : Data Primer

Responden yang memiliki umur tidak beresiko sebagian besar melakukan bounding attachment (85,7\%), dan responden yang memiliki umur beresiko sebagian besar tidak melakukan bounding attachment (77,8\%). Kemudian, responden dengan paritas multipara sebagian besar melakukan bounding attachment (88,9\%), dan paritas primipara sebagian besar tidak melakukan bounding attachment (66,7\%).

Selain itu, responden yang memiliki pengetahuan baik seluruhnya melakukan bounding attachment (100\%), sama halnya dengan respon dengan yang memiliki pengetahuan baik, responden yang memiliki pengetahuan cukup sebagian besar melakukan bounding attachment (66,7\%). Hal ini berbeda pada responden yang memiliki pengetahuan kurang yang sebagian besar tidak melakukan bounding attachment $(70 \%)$.

\section{Pembahasan}

Bounding adalah proses dimana sebagai hasil suatu interaksi terus menerus antara bayi dan orang tua (atau bayi dengan anggota keluarga lainnya) dengan kedua pihak memainkan peran aktif, suatu hubungan yang bersifat saling mencintai dan mantap tercipta, memberikan keduanya pemenuhan emosional, rasa percaya diri, stabilitas, hubungan yang bersifat saling membutuhkan (meskipun nantinya menjadi kemampuan untuk mandiri/independent) dan kapasitas untuk menyadari potensi mereka dalam kehidupan. Attachment adalah suatu perubahan perasaan satu sama lain yang paling mendasar ketika ada perasaan ketertarikan tanggung jawab dan kepuasan. Attachment dikembangkan dan dipelihara oleh kedekatan dan interaksi sesuai dengan proses perkembangan yang ditandai oleh periode kemajuan dan kemunduran. Bounding attachment adalah proses terbentuknya ikatan antara ibu nifas dan bayinya segera sesaat setelah persalinan (Nugroho \& Warnaliza, 2014).

Setelah dilakukan analisis data, penelitian ini mendapatkan adanya hubungan $(p=0,001<0,05)$ antara umur, paritas dan pengetahuan dengan pelaksanaan bounding attachment pada masa nifas.

Hal ini karena semakin cukup umur tingkat kematangan dan kekuatan seseorang akan lebih matang dalam berfikir dan 
JURNAL ILMU KESEHATAN BHAKTI HUSADA:

HEALTH SCIENCES JOURNAL, VOL. 12 No. 01, JUNI 2021

DOI: $\underline{10.34305 / \mathrm{jikbh} . v 12 \mathrm{i} 1.259}$
Ciptaan disebarluaskan di bawah

Lisensi Creative Commons Atribusi-

NonKomersial-BerbagiSerupa 4.0

Internasional. bekerja dari segi kepercayaan. Kecukupan umur sebagai akibat dari pengalaman jiwa. Hasil penelitian ini sesuai dengan hasil penelitian yang dilakukan oleh Wahyuni, (2016) dalam penelitiannya yang berjudul "Hubungan Usia dan Pendidikan Ibu Postpartum dengan Bounding Attachment di Ruang Mawar Rumah Sakit Umum Daerah Abdul Wahab Sjahranie Samarinda" didapatkan nilai $\mathrm{p}=0,027<0,05$ yang berarti ada hubungan antara umur ibu postpartum dengan bounding attachment. Alasan peneliti umur mempengaruhi ibu melakukan bounding attachment.

Berdasarkan hasil penelitian didapatkan sebagian kecil umur berisiko (22,2\%) melakukan bounding attachment, peneliti berasumsi karena variabel umur beresiko dikategorikan pada usia $<20$ tahun dan ibu yang berusia $>35$ tahun, sehingga pelaksanaan bounding attachment dilakukan oleh ibu dengan umur berisiko yang berusia $>35$ tahun. Hal ini karena ibu mempunyai naluri keibuan yang tinggi, adanya pengalaman dari masa lalunya bahwa dengan melakukan bounding attachment ternyata membuat jalinan kasih sayang antara anak dengan orang tua lebih dekat, dan mengakibatkan ibu berusaha untuk melaksanakan bounding attachment meskipun ibu mengalami kelelahan, apalagi anak tersebut merupakan anak yang diharapkan. Hal ini sesuai dengan pendapat Ayu, (2016) yang mengatakan bahwa pada umur $>35$ tahun telah berpengalaman, pada umur tersebut ibu akan lebih menyayangi anak tersebut bahkan lebih protektif sebagai anak yang sangat diharapkan.

Adapun pada umur ibu yang berisiko dan tidak melakukan bounding attachment, peneliti berasumsi karena pada umur $<20$ tahun ibu belum siap menjadi seorang ibu, sehingga setelah melahirkan ibu belum mengetahui apa manfaatnya melakukan bounding attachment, ilu lebih memikirkan perasaan lelah dan ingin istirahat sehingga ibu menolak melakukan bounding attachment. Hal ini sesuai dengan pendapat Wahyuni, (2016) yang menyatakan bahwa ibu dengan umur tersebut dapat mempengaruhi kesiapan mental ibu terhadap bayinya. Namun pada umur $>35$ tahun meskipun sudah mempunyai pengalaman, namun alat reproduksi maupun fisik ibu sudah jauh berkurang dan menurun sehingga ibu mengalami kelelahan yang mengakibatkan ibu tidak melakukan bounding attachment.

Selanjutnya berdasarkan paritas juga terdapat adanya hubungan dengan pelaksanaan bounding attachment $(p=0,001)$. Adanya hubungan ini karena ibu 
JURNAL ILMU KESEHATAN BHAKTI HUSADA:

HEALTH SCIENCES JOURNAL, VOL. 12 No. 01, JUNI 2021

DOI: $\underline{10.34305 / \mathrm{jikbh} . v 12 \mathrm{i} 1.259}$
Ciptaan disebarluaskan di bawah

Lisensi Creative Commons Atribusi-

NonKomersial-BerbagiSerupa 4.0

Internasional. dengan paritas multipara lebih banyak yang melakukan bounding attachment, dibandingkan dengan ibu dengan paritas primipara yang sebagian besar lebih memilih tidak melaksanakan bounding attachment. Hal ini sesuai dengan pendapat Caragih, (2014) yang mengatakan bahwa pengalaman seperti perawatan anak yang dialami sebelumnya dapat memperluas pengetahuan seseorang dalam bounding attachment sehingga bisa mengetahui bagaimana cara melakukan bounding attachment yang baik.

Berbeda dengan ibu dengan paritas primipara yang sebagian kecil melaksanakan bounding attachment, sesuai dengan hasil penelitian Kurnia, (2013) mayoritas ibu memiliki anak satu yang melakukan bounding attachment ini karena bayi tersebut merupakan keluarga terbaru yang hadir. Hal ini memberi ketertarikan pada ibu-ibu muda yang memiliki bayi sehingga mau melakukan bounding attachment. Akibat dari keingintahuan ibu yang lebih besar. Sedangkan pada ibu dengan paritas primipara yang tidak melaksanakan bounding attachement karena pengalaman yang masih kurang, juga disebabkan oleh kelainan yang terjadi pada bayi sehingga bayi harus dirawat terpisah dengan ibunya.

$$
\text { Bila ditinjau berdasarkan }
$$
pengetahuan, hasil dari penelitian ini menunjukkan terdapat hubungan antara pengetahuan ibu dengan pelaksanaan bounding attachment. Hal ini sejalan dengan penelitian Kurnia, (2013) didapatkan nilai $p$ yaitu 0,000 sehingga terdapat hubungan antara pengetahuan ibu postpartum dengan bounding attachment. Pelaksanaan bounding attachment lebih banyak dilakukan oleh seluruh ibu nifas dengan pengetahuan baik terkait bounding attachment. Hal ini disebabkan karena responden mengetahui tujuan, manfaat dari bounding attachement sehingga ibu mau melakukannya dengan segera. Pengetahuan ibu yang baik tersebut didapatkan ibu melalui tenaga kesehatan pada saat melakukan kunjungan dan pada saat setelah melahirkan. Berbeda dengan ibu dengan pengetahuan baik, ibu dengan pengetahuan kurang, sebagian besar tidak melaksanakan bounding attachment.

\section{Kesimpulan}

Berdasarkan hasil penelitian, terdapat adanya hubungan antara umur, paritas dan pengetahuan dengan pelaksanaan bounding attachment pada ibu nifas.

\section{Daftar Pustaka}

Astuti, H. A. (2013). Asuhan Kebidanan Nifas dan Menyusui. Jakarta : Erlangga.

Ayu. (2016). Faktor-Faktor yang Berhubungan dengan Pengetahuan Ibu 
Nifas tentang Bounding Attachment di Ruang Seureune III Dr. Zainoel Abidin Banda Aceh.

Caragih. (2014). Pengertian Karakteristik. http://www.trendilmu.com/2015/06/ pengertian-karakteristik-secaraumum.html.

Dinas Kesehatan Provinsi Jawa Barat. (2017). Profil Kesehatan Dinas Kesehatan Provinsi Jawa Barat 2017. Diskes Jabarprov.

Kuntjojo. (2010). Strategi Pembelajaran Untuk Anak Usia Dini. https://ebekunt.wordpress.com/2010/0 7/27/strategi-pembelajaran-untukanak-usia-dini/

Kurnia. (2013). Hubungan Paritas, Pengetahuan dan Pendidikan dengan Bounding Attachement pada Ibu Nifas di Rumah Sakit Ibu dan Anak Bereuneun Kabupaten Pidie. Jurnal Kesehatan, 1(2).

Nugroho, T., \& Warnaliza, D. (2014). Buku ajar asuhan kebidanan 3 nifas.

RI, K. K. (2020). Profil Kesehatan Indonesia Tahun 2019. https://doi.org/10.5005/jp/books/11257 5

Susilawati, D., Nilakesuma, N. F., \& Risnawati, R. (2020). Faktor-Faktor yang Mempengaruhi Bounding Attachment Masa Nifas. Jurnal Keperawatan Silampari, 3(2), 628637.

Wahyuni. (2016). Hubungan Usia dan Pendidikan Ibu Postpartum dengan Bounding Attachment di Ruang Mawar Rumah Sakit Umum Daerah Abdul
Wahab Sjahranie Samarinda. Jurnal Kesehatan, 4(2). http://ojs.stikesmuda.ac.id.

\section{cc) (i) (2)}

